\title{
EL COS ENTRE NÉIXER, DESNÉIXER I MORIR A MERCÈ RODOREDA, MARIA-MERCÈ MARÇAL I IMMA MONSÓ
}

\author{
MONTSERRAT LUNATI
}

\begin{abstract}
This article brings together the first chapter of La plaça del Diamant by Mercè Rodoreda; the poems which deal with the mother figure in Maria-Mercè Marçal's posthumous collection Raó del cos; and a key part of Imma Monsó's novel Un home de paraula, in which the narrator's beloved husband suddenly dies in front of her eyes. The three texts are analyzed through meaningful intertextual connections regarding the representation of the body and the problematic space for the maternal in Western culture. Moreover, they are identified as narratives of mourning in a way that problematizes the Freudian distinction between the supposedly healthy process of mourning and the allegedly pathological process of melancholia.
\end{abstract}

\section{INTRODUCCIÓ}

En aquest article examinaré tres textos de tres escriptores catalanes contemporànies: Mercè Rodoreda, Maria-Mercè Marçal i Imma Monsó. De Mercè Rodoreda, comentaré la part del primer capítol de La plaça del Diamant en què la Natàlia, tot enyorant els consells que la seva mare morta podria donar-li, vol i dol anar al ball en què coneixerà en Quimet. De Maria-Mercè Marçal, uns versos de Raó del cos que tracten la figura de la mare i enllacen, tot fent un pas més enllà gràcies a les circumstàncies extremes del subjecte poètic, amb la reflexió de la Natàlia. D’Imma Monsó he triat l'episodi d'Un home de paraula on la veu narradora "diu" la mort de l'estimat, del Cometa, una narració fragmentada i directa en la qual el cos és portat al límit i que, seguint Della Pollock, llegiré com un exemple de "performative writing". En aquest episodi central de la novel·la de dol d'Imma Monsó, la mare també hi és present, i la seva inclusió evoca lleugerament l'enyor de la Natàlia al ball de la plaça del Diamant i del desig que Marçal expressa en els seus versos.

Es tracta de tres fragments que dialoguen entre ells a través de múltiples connexions intertextuals. D'una banda, hi trobem la representació del cos com un paisatge divers i complex que, inscrit en el context sociocultural que el fa possible, indueix a reflexionar sobre qüestions d'identitat, subjectivitat, gènere o memòria. De l'altra, hi és decisiva la presència o l'absència, sovint presència in absentia, de 
la figura de la mare. Al mateix temps, entenc que tots tres són narratives de dol ("sites of memory, sites of mourning", afirma Jay Winter en el títol del seu conegut llibre), d'un dol íntim que no per això està mancat d'una dimensió política: dos d'aquests textos són un recordatori que la valoració del matern és una qüestió pendent, mentre que el tercer va influir sobre qüestions que relacionen els dos sentits de la paraula gènere (el sexual i el literari). Tots tres textos, cadascun a la seva manera, problematitzen la divisió que l'any 1917 Freud (251-68) va establir entre "dol" i "malenconia", com explicaré més endavant, i manifesten el desig explícit d'enregistrar amb paraules tant la pèrdua imposada per la mort com l'absència / presència de la mare. Els relats que en resulten constitueixen un repte important perquè permeten llegir el cos prescindint dels límits que la biologia ha imposat tradicionalment en els discursos corporals. Voldria afegir també que tots tres fragments remeten al gran tema de l'escriptura d'Hélène Cixous: “writing as reparation of loss" (Sellers xxvii).

\section{MERCÈ RODOREDA}

A l'episodi de La plaça del Diamant que m'interessa, l'enfocament del cos jove de la Natàlia i, sobretot, de la seva indumentària, fan del cos un text no sols simbòlic (la Natàlia jove, innocent i inexperta va vestida tota blanca), sinó també un text social inserit dins un context històric i cultural molt precís: la Catalunya urbana de preguerra, la Barcelona prerepublicana, encara sota Primo de Rivera, de finals dels anys 20:

Anava blanca de dalt a baix: el vestit i els enagos emmidonats, les sabates com un glop de llet, les arracades de pasta blanca, tres braçalets rotllana que feien joc amb les arracades i un portamonedes blanc, que la Julieta em va dir que era d'hule, amb la tanca com una petxina d'or. (Rodoreda 19-20)

En el capítol 1 hi ha, a més, un altre element significatiu: l'enyor per la mare morta, un enyor que evidencia la invisibilitat de la figura materna, la seva exclusió de l'ordre cultural. Abans d'anar al ball, la Natàlia sent un malestar causat per una peça oculta de la seva roba. Una peça que els altres no veuen, que només poden endevinar, els enagos:

La cinta de goma dels enagos, que havia patit molt per passar-la amb una agulla de ganxo que no volia passar, cordada amb un botonet i una nanseta de fil, m'estrenyia. Ja devia tenir un senyal vermell a la cintura, però així que el vent m'havia sortit per la boca la cinta tornava a fer-me el martiri. (Rodoreda 20) 
Dues línies més avall, quan la Natàlia s'ha adonat de les flors de paper i els músics suats de l'entarimat, el lligam entre la seva angoixa i la mare absent resulta obvi:

La meva mare morta feia anys i sense poder-me aconsellar i el meu pare casat amb una altra. El meu pare casat amb una altra i jo sense la meva mare que només vivia per tenir-me atencions. I el meu pare casat i jo joveneta i sola a la plaça del Diamant, esperant que rifessin cafeteres, i la Julieta cridant perquè la veu li passés per damunt de la música, ¡no seguis que et rebregaràs!, i davant dels ulls les bombetes vestides de flor i les cadenetes enganxades amb pasta d'aigua i farina i tothom content, i mentre badava una veu a l'orella va dir-me, ¿ballem? (Rodoreda 20)

El psiquiatre lacanià Darian Leader (145) sosté que "mourning is not just mourning the lost loved, but about mourning who we were for them", i la Natàlia sembla que ho sap molt bé. Malgrat els ecos de conte de fades amb la madrastra dolenta i el pare indiferent, aquí el que importa és el que no hi és: la mare. Una mare morta i irrepresentable. I el que no hi és esdevé enyor, desig, dol, un malestar que es tradueix en el "martiri" produït per la cinta estreta dels enagos, una peça de roba, avui antiquada, que les noies portaven per evitar qualsevol possible transparència del vestit que deixés entreveure el cos despullat. Els enagos són una resta històrica (a la cultura occidental, almenys) de les capes de teixit sota les quals les dones han hagut d'amagar el seu cos per no provocar el desig masculí (tot i que probablement s'aconseguia el contrari), en un transvassament que ha demonitzat i culpabilitzat històricament el cos femení. Són també un instrument que mostra la interiorització d'una disciplina que fa del cos de la Natàlia "a docile body" (Foucault, Discipline 135-69). És a dir, un cos que obeeix les normes dictades per una societat concreta que, a través de "the polymorphous techniques of power" (Foucault, History 11), controla el comportament dels cossos com si fossin components d'un engranatge en què l'individu té, de fet, molt poca individualitat. El cos femení es veu doblement sotmès a un rígid comportament social (aquí, indicat en el vestir) que les dones, a través de maneres sovint imposades subtilment, s'han vist obligades a assumir des de sempre.

Judith Butler, en la mateixa línia de Foucault, assenyala el pes de les pràctiques discursives que obliguen el cos a adquirir el significat de les normes que l'ordenen, pràctiques "insistent and insidious [...] sustained and regulated by various social means" (Gender 43), amb un poder que manté "its grip on bodies and their materiality, their forces, energies, sensations and pleasures" (Foucault, History 155). Però el cos incòmode de la Natàlia, ofegat per la cinta dels enagos, ens recorda que Bodies [do] Matter, si se'm permet parafrasejar el títol de Butler, que el "cos" (no pas concebut com una entitat material i prou, i qüestionant, per tant, la radicalitat del binarisme cartesià) reclama un espai al marge de la norma social. 
Aquest espai, mai atorgat, es fa evident en el capítol 1 de La plaça del Diamant per la tensió que produeix el "martiri" de la cinta dels enagos de la Natàlia, un "martiri" que s'acabarà amb l'alliberament de la cinta opressora que els aguanta. L'alliberament, però, serà ambigu.

La Natàlia declara la causa de la seva vulnerabilitat: l'orfenesa, la manca de la mare, que és també la manca de simbolització de la figura materna, sovint reduida a la complementarietat i l'ahistoricitat. És la mare absent, sense poder, no representada, excepte quan es tracta de confirmar el seu encaix dins l'ordre simbòlic, la seva funcionalitat com a canal reproductiu al servei d'aquest ordre, en una cultura que "repose sur le meurtre de la mère" (Irigaray, Le Corps 81). Com ha escrit Neus Carbonell (20), "[t]he death of Natàlia's mother exemplifies the only possible state for women in patriarchy: silence and lack of communication". Però va fins i tot més enllà: l'enyor de la Natàlia per la mare perduda és intens i converteix aquest fragment en un text de dol, un dol que, d'acord amb la premissa feminista, és personal i alhora polític perquè la mare morta no té veu, ni n'ha tinguda mai: “Mothers don't write, they are written”, recorda Susan Suleiman (356). De les mares, se'n parla, però elles rarament parlen amb veu pròpia. La dificultat de la filla per simbolitzar el dol que experimenta n'és una conseqüència: les mares, com a model social amb força, com a mirall valorat en què reconèixer-se, no existeixen (Salvo, citada a Tulanti 33).

Més endavant, quan en Quimet s'atreveix a organitzar el futur de la Natàlia, la veu narradora aplega les causes del seu malestar:

La cinta de goma clavada a la cintura i la meva mare morta i sense poder-me aconsellar, perquè vaig dir a aquell noi que el meu promès feia de cuiner al Colón i va riure i em va dir que el planyia molt perquè al cap d'un any jo seria la seva senyora i la seva reina. I que ballaríem la toia a la plaça del Diamant. (Rodoreda 21)

El món és indiferent a l'angoixa de la Natàlia i en Quimet riu, segur de si mateix. Ella continua dividida i el record de la mare se li concreta en un record del cos inabastable de la mare morta, del cos que ha esdevingut abjecte - significativament, si seguim Kristeva (Powers; Revolution) en la seva conceptualització del matern, ja que la mare ha estat la figura identificada amb el caos precultural, la figura contra la qual la filla s'ha de definir: "La cinta de la cintura semblava un ganivet i els músics ¡tararí! ¡tararí! I la Julieta desapareguda [...]. La meva mare al cementiri de Sant Gervasi i jo a la plaça del Diamant” (Rodoreda 22).

En Quimet inicia aquí la interpel-lació constant a què sotmetrà la Natàlia: li canvia el nom pel de Colometa. I la Natàlia vol fugir-ne: "vaig arrencar a córrer i ell corria al meu darrera" (Rodoreda 22). Quan l'atrapa, la Natàlia narradora manté el to epifànic, d'anagnòrisi, de molts moments d'aquest capítol i de la novel-la en general: "I la meva mare morta i jo aturada com una bleda i la cinta de 
goma a la cintura estrenyent, estrenyent, com si estigués lligada en una branqueta d'esparreguera amb un filferro" (Rodoreda 22). Com suggereix Maryellen Bieder (81): "In privileged moments her [Rodoreda's] protagonists, almost always women, see themselves simultaneously both from within and from outside, as if they were watching themselves". Per a Joan Ramon Resina (240), "reflection is always secondary to perception, it entails the alteration of the past by the perspective gained from later experience". A La plaça del Diamant, aquesta perspectiva, argumenta Resina, que s'ocupa sobretot dels aspectes temporals i comunitaris de la novel·la, està immersa en la història i té repercussions polítiques i epistemològiques perquè

[t]he impossibility of finding a narrative vantage point outside of history makes the preservation of the experienced past the more necessary if ideological categories and their reductionism are to remain themselves historical, that is to say, if they are not to preempt the future. The intention to incise the past, to preserve the personal, lived version of it as opposed to the abstract, disembodied past recorded in historical studies is thematized in the novel. (Resina 240)

La Natàlia torna a fugir i el capítol 1 acaba amb l'intent d'en Quimet d'apropiar-se de la seva veu:

I vam sortir al carrer Gran, i jo amunt, i ell al meu darrera i tots dos corrent, i, al cap d'anys, encara de vegades ho explicava, la Colometa, el dia que la vaig conèixer a la plaça del Diamant, va arrencar a córrer i davant mateix de la parada del tramvia, ipataplaf! Els enagos per terra. (Rodoreda 22-3)

Aquests enagos, com si fossin una extensió del cos de la Natàlia, es neguen, podríem dir, a continuar oprimint-la. "Bodies are not inert; they function interactively and productively. They act and react. They generate what is new, surprising, unpredictable”, diu Elizabeth Grosz a Volatile Bodies (xi). La correguda de la Natàlia, l'allibera dels enagos, però la contradicció és que, sense enagos, el cos encara està més exposat perquè en el seu entorn no ha canviat res.

El primer capítol és un exemple important de com el cos és un element important en la construcció de la subjectivitat de la protagonista de la novel·la tot i que no és l'únic. Com bé assenyala Eva Bru, La plaça del Diamant s'ha llegit sobretot com una novellla psicològica, però la corporalitat també hi és molt present. Ella mateixa ho fa avinent en observar la relació que la Natàlia estableix amb les olors del mercat: és el cos de la Natàlia el que fa possible "to evoke the very pulse of pre-Civil War daily life in the Gràcia neighbourhood, activating, in turn, the reader's historical memory" (Bru 86). Efectivament, al llarg de la novel·la, el cos de la Natàlia s'incorpora al paisatge urbà de maneres molt significatives. Així, la trobem unes quantes vegades corrent i patint pels carrers de 
Gràcia, com per exemple quan passa com boja pel carrer Gran en tornar a casa després d'haver deixat els nens sols per anar a treballar: "de poc que vaig a parar a sota d'un tramvia" (Rodoreda 114); o quan, acabada la guerra, desesperada, decideix matar-se i matar els seus fills: "Vola, vola, Colometa, que darrera teu hi ha tota la pena del món" (187). Només al final, un cop ha fet el seu crit, tan carnal i primari, i ha inscrit "Colometa", el nom que en Quimet li va posar, a la paret de la casa on havia viscut amb ell, no aconsegueix establir una relació diferent amb els carrers de Barcelona. Per això aquell matí, quan va cap a casa, para esment que no l'atropellin: "Damunt de la pedra del cantell de l'acera del carrer Gran, vaig mirar amunt $i$ avall que no vinguessin tramvies i vaig travessar corrent, i quan vaig arribar a la banda bona encara em vaig girar a mirar per veure si em seguia aquella mica de no-res que m'havia fet tornar tan boja” (250). Tampoc no podem oblidar la representació del cos prenyat de la Natàlia:

Quan em despertava em mirava les mans ben obertes davant els ulls i les feia moure per veure si eren meves i si jo era jo. [...] Se m'inflaven les mans, se m'inflaven els turmells i només faltava que em lliguessin un fil a la cama i m'engeguessin a volar. [...] era com si m'haguessin buidat de mi per omplir-me d'una cosa molt estranya. Algú molt amagat s'entretenia a bufar-me per la boca i jugava a inflar-me. [...]. (Rodoreda 74,75 )

O el seu cos quan va de part: "I el primer crit em va eixordar. Mai no hauria pensat que la meva veu pogués anar tan lluny i durar tant. I que aquell patir em sortís fet crits per la boca i criatura per baix" (Rodoreda 77).

Curiosament, aquestes (i d'altres) experiències de la Natàlia es corresponen amb la concepció de la maternitat com una experiència alienant per a la dona que va formular Simone de Beauvoir i que va exercir una influència notable sobre el feminisme dels anys seixanta i setanta:

But pregnancy is above all a drama that is acted out within the woman herself. She feels it as at once an enrichment and an injury; the foetus is a part of her body, and it is a parasite that feeds on it; she possesses it, and she is possessed by it. A new life is going to manifest itself and justify its own separate existence, she is proud of it; but also she feels herself tossed and driven, the plaything of obscure forces. It is especially noteworthy that the pregnant woman feels the immanence of her body at just the time when it is in transcendence; it turns upon itself in nausea and discomfort. (Beauvoir 512)

A La plaça del Diamant, els cossos masculins també són significatius: el d'en Quimet, quan fa una tènia en un episodi que s'ha interpretat com un exemple de l'enveja masculina per la capacitat reproductiva de les mares (Carbonell 21): "I en Quimet deia que ell i jo érem iguals perquè jo havia fet els nens i ell havia fet un cuc de quinze metres de llargada" (Rodoreda 99). O el cos "esguerradet" (252) de l'Antoni després de la guerra, sobretot a l'escena final de la novel·la, quan la Natàlia 
i ell fan l'amor amb ella com "the active partner", una escena que per a Josep-Anton Fernàndez (109) evoca un amor homosexual: "i abans d'adormir-me, mentre li passava la mà pel ventre, vaig topar amb el melic i li vaig ficar el dit a dintre per tapar-l'hi, perquè no se'm buidés tot ell per allí ...” (Rodoreda 252). Encara que "in patriarchal societies the male body [has been] ostensibly deproblematized [and] veiled from inquiry" (Brooks 15), és ben clar que hi hauria moltes coses a dir. Però el que ara m'interessa especialment és la Natàlia filla. L'absència irreparable de la mare, el desig de la mare prohibida per la psicoanàlisi clàssica, la mare que el subjecte ha de deixar enrere per tal d'esdevenir un ésser social, es presenta com a molt problemàtica en diversos textos de Rodoreda. A La plaça del Diamant no allibera la Natàlia, sinó que la perjudica. I l'abandona, indefensa, en mans d'una cultura masculina representada per en Quimet. La pregunta ominosa que aquest li fa a cau d'orella, aquest "ballem?" que acaba la cita que he transcrit abans, és el primer indici de la interpel-lació que definirà la relació entre un i altra, fins i tot després de la mort d'en Quimet, quan la imatge d'ell la perseguirà en una etapa que es caracteritza per l'agorafòbia de la Natàlia i que no s'acaba fins que ella aconsegueix parlar, al parc, amb altres dones, del passat com una etapa tancada que, tot i ser amarga, ja no la paralitza. Aquesta actitud envers el passat recorda la definició freudiana (Freud 251-68) del concepte de "dol", que implica una dinàmica progressiva, d'acceptació, una dinàmica saludable i oposada a la de de la "malenconia”, que implica un procés patològic d'introspecció que atrapa el subjecte en el passat i li impedeix d'avançar.

No obstant això, la distinció entre "dol" i "malenconia" no és tan nítida com Freud la va plantejar al principi i ha estat repetidament qüestionada. L'any 1923, a "The ego and the id", el mateix Freud va matisar-la posant en relleu la naturalesa melancòlica de l'ego, que explicaria la resistència del subjecte a abandonar l'objecte perdut. Com assenyalen David Eng i David Kazanjian (4) en indicar aquesta contradicció, "the work of mourning is not possible without melancholia" ja que l'ego "is composed of residues of its accumulated losses". A The Cultural Politics of Emotion, Sarah Ahmed afirma que "Letting go of the lost object may seem an ethical as well as a 'healthy' response to the alterity of the other. [...] But the idea that 'letting go' is better has been challenged" (159). Segons Eng i Kazanjian (3-4), no es tractaria d'entendre la "malenconia" com una fixació malaltissa amb el passat, sinó de mantenir amb el passat una relació més oberta, menys radical, més lleial; de mantenir "a continuous engagement with loss and its remains", perquè ens cal "a better understanding of melancholic attachments to loss [which] might depathologize those attachments, making visible not only their social bases but also their creative, unpredictable, political aspects".

Aquesta "malenconia" que comporta una relació amb un passat que no es vol deixar enrere però que no és forçosament una relació patològica, és la que es fa 
palesa en l'enyorament de la Natàlia per la mare morta (i, en un dol diferent, un dol per l'estimat, també s'observa en Un home de paraula, d'Imma Monsó). Atès l'abast polític de la discriminació (o l'“assassinat”) de la mare en la nostra cultura, el dol no resolt de la Natàlia per "the lost Mother object" (Kaplan 124), la mare que ha calgut sacrificar a l'entrada de l'ordre simbòlic, adquireix una inevitable dimensió social que ens fa llegir-lo políticament. Com espero haver assenyalat, el capítol primer de La plaça del Diamant combina de manera magistral el dol melancòlic per la mare perduda amb una representació del cos femení, sempre emmarcat en una cultura determinada, que enllaça amb reflexions crítiques posteriors sobre el cos.

\section{MARIA-MERCE MARÇAL}

La mare que cal alliberar dels discursos patriarcals que l'han convertida en un llast per a la filla, és la mare que el subjecte poètic de Raó del cos (2000), de Maria-Mercè Marçal, vol recuperar. Per designar la mort com el retorn al ventre de la mare, Marçal s'inventa una paraula nova, "desnéixer", una paraula d'inspiració feminista perquè a Raó del cos el retorn al ventre matern no és només una manera d'enfrontar-se amb la mort, sinó també el reconeixement de la discriminació cultural contra el matern. En comptes de deixar la mare enrere per tal d'esdevenir un ésser social, segons la pauta de la psicoanàlisi clàssica, el subjecte poètic de Marçal la recupera i hi busca un últim refugi, tot adonant-se de fins a quin punt la mare ha estat arraconada per una cultura masculina amb la qual les filles sovint han collaborat en adoptar l'actitud que Mimi Schippers anomena "hegemonic femininity", una actitud complice amb al patriarcat, que fa de la mare la figura negativa contra la qual la filla s'ha de definir, aquella actitud que Adrienne Rich (235) considera "matrofòbica" (entenent la matrofòbia com la por que sent la filla de ser com la mare, el rebuig de la mare per part de la filla).

Marçal crea un sinònim de morir, "desnéixer", una paraula intensament carnal per definir la mort com un retorn a l'úter matern, "la matriu de déu" (Marçal 41), un déu en minúscula però la mare com a font de vida perquè "déu" és un parònim de "deu" a "[l]a deu primera, mare" del vers de Marçal (73), una font natural d'aigua, de vida.

El subjecte poètic busca la complicitat de la mare en aquest dol contingut i coratjós per la pròpia mort: "Mare, no ploris per mi, mare, / plora amb mi" (Marçal 73). Aquest "amb", una preposició inclusiva, constitueix una arma contra la matrofòbia i resumeix com cap altra paraula tota la filosofia dels versos sobre la relació del subjecte poètic amb el matern a Raó del cos. La preposició indica com la veu poètica busca el retrobament amb la mare, rebutjant els prejudicis de què la seva figura ha estat objecte. La certesa d'una mort propera supera l'angoixa 
buscant i retrobant una mare que ha estat culturalment prohibida. El concepte de "desnéixer" és clau: serà el cos de la mare qui rebrà aquest subjecte poètic després de la mort, quan perdi "forma i contorns", i la mort no serà pèrdua. A l'inrevés del que creu el subjecte poètic de "Cançó d'albada", a un poema de Salvador Espriu (287) inclòs a El caminant i el mur (1954), "Car tot, en un moment / et serà pres", la veu poètica de Marçal assegura que, gràcies a la companyia de la mare "Res no et serà pres", que la mort serà només un anar-se'n sense dolor:, "l'instant d'obrir / dòcilment la mà / i alliberar / la memòria de l'aigua / perquè es retrobi aigua / d'alta mar" (Marçal 39).

La mare és "vida i mortalla" (Marçal 51) en un poema en què el to religiós resulta escaient perquè s'aplica a la mare, figura de sacrifici cultural, per a la qual s'adapten els rituals catòlics del sagrament de la comunió, que converteix pa i vi en "cos" i "sang" (51). Constatar que el cos serà sempre sacrificat, com en el ritual catòlic de l'Eucaristia, no calma l'angoixa, més aviat desferma o, en el cas de Marçal, afina, intensifica els sentits. Ho afirma Jean-Luc Nancy (4) tot reflexionant sobre la importància del cos a partir de la frase de culte Hoc est enim corpus meum: "Sensory certitude, as soon as it is touched, turns into chaos, a storm where all senses run wild”. Els versos nous i radicals de Raó del cos sobre la mort, la mare i el cos que les uneix poden llegir-se molt bé com una esplèndida i renovadora tempesta textual.

El subjecte poètic de Raó del cos es culpa d'haver estat partícip d'una cultura masculina, agressiva, penetrant, que discrimina les mares: ha tingut "el cos empalat / en eix de fosques pàtries", però ha reaccionat i els seus ulls, "orfes de llum", han buscat "pàtries més benignes". Aquestes "pàtries més benignes" només poden ser la "màtria abolida" (Marçal 49), un altre neologisme, igualment referit al cos, per donar nom a allò que no ha trobat espai per simbolitzar-se en el llenguatge del pare.

A Raó del cos el subjecte poètic constata i lamenta l'existència d'aquesta cultura en què preval una "feminitat hegemònica", i amb una al-lusió bíblica a Sant Pere admet que "T'he negat / mare / tres cops / i cent" (55). Però cap gall no ho ha cantat: "Són cegues, sordes, mudes / les nostres traïcions" (55), és a dir, la invisibilitat cultural, la no simbolització del femení, i, concretament, del matern. És clar que mare i filla, "cosides l'una a l'altra” (les metàfores de "cosir" són molt importants a Raó del $\cos )^{1}$ ara aixequen l'espasa de "la sang del nostre silenci" (56). Es tracta d'una lluita que les ha deixades exhaustes i és el cos que metafòricament ho reflecteix: "I es poden comptar / tots els nostres ossos" (56), perquè a Marçal el cos és sempre un cos sexuat, i un cos sexuat que escriu (Ibarz 10), és a dir, un cos que no és neutre (com s'ha volgut tradicionalment), sinó conscient del seu sexe / gènere, que no nega el que és específic del cos femení perquè fer-ho contribuiria a la seva discriminació. 
A Raó del cos, la fantasia d'una mare recuperada de la ruptura edípica no vol excloure el llenguatge, i aquest és un aspecte cabdal. La lluita per simbolitzar, per crear sentit, és una "cruilla" en què els "ossos, esculls de l'alba" són "la paraula" (57), és a dir, que el cos fet llenguatge ha de formar part d'aquest renaixement, d'aquesta "alba". Si abans la "paraula viva" ha estat "inarticulada", ara s'ha de dir, com fa el subjecte poètic, i és igual que el llenguatge, la seva capacitat de representació, vagi inevitablement associat amb un desig irrealitzable, amb una altra mena de fantasia, que la "paraula" sigui "[p]orta entre mar / i mar /[...]: / exili de l'exili" (43): la veu poètica ho intenta i aquest és el seu vers.

\section{IMMA MONSÓ}

Dir, o lluitar per dir, és precisament el que fa Imma Monsó en narrar el fragment més difícil, més dolorós, i també el més decisiu, de la seva novellla de dol Un home de paraula (2006), en què el Cometa, el marit, el company, l'amor de la narradora, es mor d'un atac de cor que ha manifestat uns símptomes que no s'han sabut llegir. El fragment és extraordinari, en el sentit més complex de la paraula. La narradora contempla la mort de l'estimat sense poder fer-hi res: "Puc morir amb l'altre, però mai 'per' l'altre, per molt inalienables que siguin els lligams o l'afinitat que ens uneixin", diu George Steiner (24). La veu narradora d'Un home de paraula exerceix una doble funció: viu l'experiència i, al mateix temps, l'observa, diu i reflexiona a la vegada. És això el que provoca un efecte molt freqüent a l'escriptura de Monsó: la perplexitat, una perplexitat que en un altre lloc (Lunati 179-89) he relacionat amb el concepte cartesià d'admiration que Luce Irigaray (Éthique 75-84) apropia per al feminisme en articular la seva proposta d'una ètica de la diferència sexual, i que es podria definir com una manera de mirar el teu altre (sexual) com si sempre fos la primera vegada que el veiessis per tal de no objectificar-lo. Monsó confessa que "La perplexitat és el que em fa escriure. [...] l'actitud filosòfica per excel-lència. La perpètua curiositat, el moment en què et fas totes les preguntes" (Monso qtd. in Lunati 36). I, a propòsit d'Un home de paraula, concreta: "La perplexitat és el motor del llibre" (Monso qtd in Lunati 36). En el moment del "dolor atroç, el dolor en brut" (Monsó 14), la veu no para de narrar, de "dir"; el dolor no substitueix la perplexitat, s'hi afegeix:

I llavors no sé com, no sé quan, no sé ben bé si encara mira la pel-lícula o ja ha acabat fa una estona, ell s'inclina cap a mi d'una manera estranya.

D’una manera inusual.

Això era. 
Això és.

Ha arribat.

I no, no la reconec. Ni tan sols ara.

«¿Què passa, amor, què passa?»

(¿Ha de ser així?)

Ell no diu res.

La seva mirada serena.

Neta. (Monsó 53-54)

El silenci i la "mirada serena" i "neta" de l'home de paraula, de l'home fet de paraules de la novel-la, són allò que marca la distància amb l'estimat com l'altre inabastable, amb el cos que esdevé estrany, foraster, malgrat "the illusory belief that meaning is to be found in bodily knowledge of the other" (Brooks 118). El cos de l'estimat ja és un viatger de la mort, només memòria, inaccessible per primera vegada i per sempre a l'inici del dol, quan "el dia es fa nit" per a la narradora, com en el famós Sonet 23 de John Milton ("Methought I saw my late espoused saint", 1673) en què el subjecte poètic plora la mort de l'esposa jove:

Her face was veil'd, yet to my fancied sight

Love, sweetness, goodness, in her person shin'd

So clear as in no face with more delight.

But Oh! As to embrace me she inclin'd,

I wak'd, she fled, and day brought back my night.

En aquest fragment d'Un home de paraula, tan sintètic però tan complex, Monsó textualitza un esdeveniment biogràfic combinant formes diverses del discurs narratiu (la descripció, la interrogació retòrica, la narració fragmentada, la puntuació significativa...) tot preguntant-se, en fer-ho, si cadascuna d'elles, o totes juntes, arriben a crear sentit, o almenys el sentit que la narradora s'esforça per comunicar al llarg del llibre: "fa dies que ell és (com n'hi diuen d'això, 'mort?')" (Monsó 15). La mateixa estranyesa davant el llenguatge i la seva (in)capacitat per expressar apareix a A Grief Observed, el llibre de dol per la seva dona de C. S. Lewis (15): "She died. She is dead. Is the word so difficult to learn?"

El concepte de "performative writing" tal com l'entén Della Pollock ens pot ajudar a llegir aquest fragment d'Un home de paraula: "Writing as doing displaces writing as meaning; writing becomes meaningful in the material, dis/continuous act of writing" (Pollock 75).

Pollock (73-74) té present que Adorno es pregunta "[if] there [is] any meaning in life when men exist who beat people until the bones break in their bodies?" i que escriu "on the edge of referentiality, at once referring [this] question to the atrocities of the Second World War and anticipating, on those grounds, the collapse of both referential and normative meaning systems". Per això Peggy Phelan 
(12-13) considera que el "performative writing” de Pollock no és únicament una qüestió d'estil: "It is an inquiry into the limits and possibilities of the intersection between speech and writing. [...] [It] seeks to extend the oxymoronic possibilities of animating the unlived that lies at the heart of performance as a making”.

En aquest fragment, l'escriptura de Monsó manifesta dues de les característiques del "performative writing", característiques que subratllen l'autoconsciència del text. Es tracta d'una escriptura "evocative": "It does not describe, in a narrowly reportorial sense, an objectively verifiable event or process but uses language like paint to create what is self-evidently a version of what was, what is, and/or what might be" (Pollock 80). Crec que la imatge d'escriure com si la escriptura fos una pintura és molt adequada en el cas de Monsó. Es tracta sobre tot d'una pintura / escriptura no figurativa, més interessada en presentar una imatge fragmentada que defuig les convencions del realisme. La veu narradora dóna una versió del fets, no pot ser d'altra manera, només es pot parlar des d'un lloc concret, en aquest cas, des de l'espai de la proximitat i el dolor.

Pollock també afirma que es tracta d'una escriptura conscientment "metonymic":

It is a self-consciously partial or incomplete rendering that takes its pulse from the difference rather than the identity between the linguistic symbol and the thing it is meant to represent. It dramatizes the limits of language [...] in an endlessly open field of representation. It recognizes the extent to which writing displaces, even effaces "others" and "other-worlds" with its partial representations of them, not only not revealing truths, meanings, events, "objects," but often obscuring them in the very act of writing, securing their absence with the substitutional presence of words, effectively making absent what mimetic/metaphoric uses of language attempt to make present. (Pollock 82-83)

La fragmentació del relat pot obscurir la comprensió, de fet, ho fa. El fragment de la novellla que estic tractant s'ha de llegir més d'un cop per poder valorar la intensitat d'una escriptura que mostra la dificultat de dir, en particular, quan el que es vol dir comporta dolor. La veu narradora no intenta ser convencional, menys encara sentimental. Produeix, en canvi, una narració esquinçada, conscientment esbiaixada, parcial, una narració que dramatitza els límits del llenguatge, que entén la representació com un desplaçament (com també ho admetia Maria-Mercè Marçal en parlar de la paraula en termes d'exili).

En dir la mort de l'estimat, l'actualització del passat converteix la narració en una performance en el sentit més respectuós del mot, una difícil posada en escena que inaugura el dol desenrotllat en el llibre. I en el centre de l'escena hi ha el cos que ha fugit cap a la mort. Com explicar des de la primera fila una transformació d'aquesta magnitud que, a més, conté una sorpresa tan dolorosa que pot liquidar les sorpreses per sempre. Tanmateix, la veu narradora ho fa, $\mathrm{i}$ ho fa en una novel-la l'escriptura de la qual s'inicia com l'expressió d'un dol personal. Ara bé, com que 
aquest dol personal és un dol escrit, i escrit inevitablement per als altres, esdevé un dol collectiu, on els altres hi poden trobar el seu. El fet mateix de publicar-lo el fa històric, almenys en relació amb la història de la literatura catalana contemporània, i sobretot de la literatura d'autora, ja que l'èxit d'Un home de paraula va conferir visibilitat i respecte a aquest tipus de narrativa i va permetre, per exemple, que un altre llibre de dol escrit per una dona, Trena de cendra, de Carme Guasch, que s'havia publicat amb poc èxit l'any 1984, es tornés a editar l'any 2008.

Després de la irrupció brutal i destructiva de la mort en la quotidianitat amable de les seves vides, i havent-se enfrontat amb la representació impossible d'aquesta mort, la narradora d'Un home de paraula continua: "Surt de mi una mena d'autòmata. Algú que telefona, algú que, inexplicablement, coordina els moviments, algú que truca i parla i torna a trucar perquè l'ambulància no arriba i suporta contestadors automàtics i busca les claus de la porta del jardí” (Monsó 54).

Enmig del desconcert i la perplexitat, arriben, gairebé al mateix temps, l'ambulància i l'àvia, la mare de la narradora. La mare / àvia ha vingut per endur-se la filla del Cometa i la narradora. La nena, en un gest anacrònic en el mateix instant de produir-se, un gest d'un passat que acaba de desaparèixer, reclama el violí per una lliçó que té l'endemà:

Quan l'àvia s'emporta la nena pel carrer mullat, va arribant l'ambulància, lenta i silenciosa, i la nena es gira de cop just abans de desaparèixer per la cantonada. "El violí, vull el violí", sento que diu la veueta. Els seus ulls topen amb la llum taronja que inunda el carrer, just abans que l'àvia l'estiri i desapareguin per la cantonada. (Monsó 54)

A The Sea (221-22), una novel-la de John Banville on preval la representació d'un dol "melancòlic" com a única opció ètica, llegim: "Memory dislikes motion, preferring to hold things still". Com per al narrador de The Sea, en aquest episodi de la novel-la d'Imma Monsó, el carrer acolorit per la llum de l'ambulància que travessa la nit és una imatge que s'ha conservat intacta en la memòria de la narradora. Aquesta imatge del passat en portarà d'altres, igualment intactes: un dol recorda un altre dol, en aquest cas el del pare de la narradora, en un diàleg de dols, un contagi d'afectes (molt important a la novel-la però que ara ens apartaria de l'aspecte que tractem). Aquí la mare / àvia ha vingut a ajudar, o a intentar ajudar, a protegir, o a intentar protegir, la nena, que ha estat expulsada despietadament del paradís, potser utòpic, de la infantesa. La presència gairebé fugaç de la mare / àvia al final d'aquest fragment és fonamental. Una altra novel·la de Monsó, Tot un caràcter (2001), és un exercici contra l'exclusió del subjecte femení centrat precisament en la construcció cultural de les mares. La figura materna no hi és un subjecte ahistòric, marcat per la biologia o per la complementarietat, sinó un personatge que venç les limitacions que les societats tradicionals imposen al paper social de les mares. Monsó inclou la veu de la mare al final de Tot un caràcter, i ho 
fa amb la ironia pròpia de la seva escriptura, recuperant, divertida, el llenguatge que mare i filla havien emprat en el passat. A Tot un caràcter, l'ús enginyós i creatiu del llenguatge per part de la mare va molt més enllà de les suposades ruptures del simbòlic que, segons el concepte del semiòtic de Kristeva, és possible a través de la poesia o la maternitat, però que per a Butler serien només "tactical subversions and displacements" (Gender 86) o "temporary subversions" (Gender 88). Tot un caràcter recupera la figura materna com a subjecte històric i com a subjecte que desitja (Lunati 195-244). La mare d'aquest fragment d'Un home de paraula que he analitzat és més subtil i no té veu, però, Monsó, en inscriure-la en el relat com una presència que ajuda, que entén la situació en què es troba la narradora i acudeix a fer el que cal en el moment precís, mostra que la mare pot ser còmplice, que és una mare "amb", com la que simbolitza Marçal, i que la matrofòbia, aquesta arma del patriarcat i la misogínia més recalcitrant, ni és norma ni ha de dividir la mare i la filla.

Aquí no hi ha la traïció a la mare de què es culpa el subjecte poètic de Marçal, i sí, en canvi, una textualització específica i inclusiva de la figura materna, com a Rodoreda, com a Marçal, amb "the forcible affect of language", per dir-ho com Denise Riley (1), perquè, com hem vist en el fragment corprenedor de la mort del Cometa, "language exerts a torsion on its users [but] does not immobilize them, let alone strangle them", i perquè el pitjor que podríem fer és acceptar la presència d'aquesta mare com una cosa "natural".

MONTSERRAT LUNATI

Cardiff University

\section{NOTES}

1 Per exemple, quan s'utilitzen imatges de cosir en relació amb la memòria, que sempre destria els records, que és selectiva d'una manera inconscient, com "una sargidora cega" i "cus" amb "fils d'oblit" (Marçal 17), indicant que el que es recorda i el que s'oblida van inextricablement units, que formen part del mateix procés. $O$ en un altre poema en què la cicatriu de la mastectomia esdevé una "[c]remallera / de carn" (Marçal 19), un poema en què el subjecte parla de l'exili simbòlic que la malaltia comporta i en què els dinou versos curts, alguns d'una sola paraula, el converteixen en un poema visual, un cal-ligrama de la cicatriu. 


\section{REFERÈNCIES}

Ahmed, Sara. The Cultural Politics of Emotion. Edimburg: Edinburgh University Press, 2004.

Banville, John. The Sea. Londres: Picador, 2010.

Beauvoir, Simone de. The Second Sex. 1949. Trad. H. M. Parsley. Londres: Vintage, 1997.

Bieder, Maryellen. "Silent women: Language in Mercè Rodoreda". Voices and Visions: The Words and Works of Mercè Rodoreda. Ed. de Kathleen McNerney. Selinsgrove, PA: Susquehanna University Press; Londres: Associated University Presses, 1999. 80-97.

Brooks, Peter. Body Work: Objects of Desire in Modern Narrative. Cambridge, MA: Harvard University Press, 1993.

Bru-Domínguez, Eva. Beyond Containment. Corporeality in Mercè Rodoreda's literature. Oxford/Bern: Peter Lang, 2013.

Butler, Judith. Bodies That Matter: On the Discursive Limits of "Sex". Nova York i Londres: Routledge, 1993.

- Gender Trouble: Feminism and the Subversion of Identity. Nova York i Londres: Routledge, 1990.

Carbonell, Neus. "In the name of the mother and the daughter: The discourse of love and sorrow in Mercè Rodoreda's La plaça del Diamant". The Garden across the Border: Mercè Rodoreda's Fiction. Ed. de Kathleen McNerney i Nancy Vosburg. Selinsgrove, PA: Susquehanna University Press; Londres i Toronto: Associated University Presses, 1994. 17-30.

Eng, David L., i David Kazanjian, eds. Loss: The Politics of Mourning. Berkeley, CA. i Londres: University of California Press, 2003.

Espriu, Salvador. Obres Completes. I. Poesia. Barcelona: Edicions 62, 1968.

Fernàndez, Josep-Anton. "The angel of history and the truth of love: Mercè Rodoreda's La plaça del Diamant”. The Modern Language Review 94.1 (1999): 103-9.

Freud, Sigmund. "The ego and the id". 1923. The Standard Edition of the Complete Psychological Works of Sigmund Freud. Vol XIV. Londres: Hogarth Press, 1955. 1-59.

-. "Mourning and melancholia". On Metapsychology: The Theory of Psychoanalysis. 1917. The Penguin Freud Library. Vol. IV. Londres: Penguin, 1984. 251-68.

Foucault, Michel. Discipline and Punish: The Birth of the Prison. 1963. Trad. Alan Sheridan. Nova York: Vintage Books, 1995.

- The History of Sexuality. Vol. 1, An Introduction. 1976. Trad. Robert Hurley. Londres: Penguin Books, 1990.Grosz, Elizabeth. Volatile Bodies: Toward a Corporeal Feminism. Bloomington i Indianapolis: Indiana University Press, 1994.

Guasch, Carme. Trena de cendra. 1984. Barcelona: Columna, 2008.

Ibarz, Mercè. "Silencis, interrupcions, mites”. Maria-Mercè Marçal, Sota el signe del drac. Proses 1985-1997. Ed. de Mercè Ibarz. Barcelona: Proa, 2004. 7-18.

Irigaray, Luce. Éthique de la différence sexuelle. París: Les Éditions de Minuit, 1984.

—. Le Corps-à-corps avec la mère. Montreal: Éditions de Pleine Lune, 1981.

Kaplan, Ann E. Motherhood and Representation: The Mother in Popular Culture and Melodrama. Londres i Nova York: Routledge, 1992.

Kristeva, Julia. The Powers of Horror: An Essay on Abjection. 1980. Trad. Leon S. Roudiez. Nova York: Columbia University Press, 1982. 
—. Revolution in Poetic Language. 1974. Trad. Margaret Waller. Nova York: Columbia University Press, 1984.

Leader, Darian. The New Black: Mourning, Melancholia, and Depression. Londres: Hamish Hamilton, 2008.

Lewis, C. S. A Grief Observed. Londres: Faber \& Faber, 1961.

Lunati, Montserrat. Imma Monsó: la narrativa de la ironia i la diferència. Vic: Eumo/ Universitat de Vic, 2007.

Marçal, Maria Mercè. Raó del cos. Ed. de Lluïsa Julià. Barcelona: Edicions 62, 2000. Trad. com The Body's Reason per Montserrat Abelló I Noèlia Diaz-Vicedo. Londres: Francis Bootle, 2014.

Milton, John. "Methought I saw my late espoused saint”. 1673. The Poetry Foundation. <http://www.poetryfoundation.org/poem/174012>. Consultat el 27 d'abril de 2016.

Monsó, Imma. Tot un caràcter. Barcelona: La Magrana, 2001.

-. Un home de paraula. Barcelona: La Magrana, 2006. Trad. com A Man of his Word per Maruxa Relaño I Martha Tennent. Madrid: Hispabooks, 2014.

Nancy, Jean-Luc. Corpus. Edició bilingüe. Traducció a l'anglès de Richard A. Rand. Nova York: Fordham University Press, 2008.

Phelan, Peggy. "Introduction: The ends of performance". The Ends of Performance. Eds. Peggy Phelan i Jill Lane. Nova York i Londres: New York University Press, 1998. 1-22. Pollock, Della. "Performing writing". The Ends of Performance. Eds. Peggy Phelan i Jill Lane. Nova York i Londres: New York University Press, 1998. 73-103.

Resina, Joan Ramon. "The link in consciousness: Time and community in Rodoreda's La plaça del Diamant". Catalan Review 2.2 (1987): 225-46.

Rich, Adrienne. Of Woman Born: Motherhood as Experience and Institution. Londres: Virago, 1986.

Riley, Denise. Impersonal Passion: Language as Affect. Durham, NC: Duke University Press, 2005.

Rodoreda, Mercè. La plaça del Diamant. 1962. Barcelona: Club Editor, 1972. Trad. com The Pigeon Girl per Eda O'Shiel. Londres: André Deutsch, 1967; The Time of the Doves per David H. Rosenthal. Minneapolis, MN: The Graywolf Press, 1986; In Diamond Square per Peter Bush. Londres: Virago, 2013.

Schippers, Mimi. "Recovering the feminine other: Masculinity, femininity and gender hegemony". Theory and Society 36.1 (2007): 85-102.

Sellers, Susan. "Introduction”. The Hélène Cixous Reader. Ed. de Susan Sellers. Nova York: Routledge, 1994. xxvi-xxxiv.

Steiner, George. Deu raons (possibles) de la tristesa del pensament. 2005. Trad. Berdagué Costa. Barcelona: Arcàdia, 2006

Suleiman, Susan Rubin. "Writing and motherhood". The (M)other Tongue: Essays in Feminist Psychoanalitic Interpretation. Ed. de Shirley Nelson Garner, Claire Kahane i Madelon Sprengnether, Ithaca, NY, i Londres: Cornell University Press, 1985. 352-77.

Tulanti, Maddalena, Madri e figlie. Ieri e oggi. Ed. Dacia Maraini, Anna Salvo, i Silvia Vegetti Finzi. Roma: Laterza, 2003.

Winter, Jay. Sites of Memory, Sites of Mourning: The Great War in European Cultural History. 1995. Cambridge: Cambridge University Press, 2014. 